Z. Klin. Chem. Klin. Biochem.

13. Jg. 1975 , S. $549-552$

\title{
Automated Analysis of Total Urinary Hydroxyproline Based on Resin-Catalysed Hydrolysis
}

\author{
By S. Orloff, V. H. Rao and L. Verbruggen \\ Laboratory of Rheumatology, Brugmann University Hospital (V.U.B. - U.L.B.), Brussels, Belgium
}

(Eingegangen am 22. Februar/13. Juni 1975)

Summary: An automated method for the analysis of total urinary hydroxyproline using strong cation resin tablets of Hypronosticon is described for use in a clinical laboratory and the results are compared with those obtained by other methods.

Even though good recoveries are obtained using the technique described in the present work by adding the internal standards either before or after hydrolysis of urine, the present method gave consistently lower values of urinary hydroxyproline compared with a manual and an automated method.

\section{Mechanisierte Analyse von Gesamt-Hydroxyprolin im Harn nach Ionenaustauscher-katalysierter Hydrolyse}

Zusammenfassung: Eine mechanisierte Methode zur Analyse des gesamten Hydroxyprolins im Harn mit Hilfe der stark sauren Kationenaustauscher-Tabletten von Hypronosticon wird für den Gebrauch im klinischen Laboratorium beschrieben. Die Ergebnisse werden mit den mit anderen Methoden erhaltenen verglichen.

Mit der beschriebenen Methode werden gleich gute Wiederfindungsraten erhalten, wenn der interne Standard vor oder nach Hydrolyse zugefügt wird. Die angegebene Methode ergibt geringere Hydroxyprolinwerte als die manuelle und die mechanisierte Vergleichsmethode.

\section{Introduction}

As hydroxyproline is found almost exclusively in collagen, its excretion in the urine can be used to follow the changes in the metabolism of collagen $(1,2)$. In the last decade, several manual as well as automated methods for the determination of hydroxyproline have been published in the literature. In urine, up to $95-97 \%$ of the hydroxyproline is accounted for in peptide-bound form and $5-3 \%$ in free form (3). Therefore, for the estimation of total hydroxyproline in urine, the peptide-bound form should be released by acid hydrolysis. During the hydrolysis, large amounts of humins are formed which have to be removed along with the other interfering compounds. Recently Goverde \& Veenkamp (4) have reported a method for the assay of total urinary hydroxyproline in which the hydroxyproline-containing material from urine is bound to the strong cation exchange resin tablet and the interfering compounds are eliminated by subsequent washing.
Comparison of the manual method of Goverde \& Veen kamp (4) with the automated method of Grant (5) for the determination of hydroxyproline in urine revealed a good correlation $(\mathrm{r}=0.9805)$ between the two techniques (6). Further the same authors have also reported (7) that these two methods were sufficiently specific and suitable for use in the routine clinical chemical laboratory by comparing the results with the manual reference method of Kivirikko et al (8).

Since we reported in a previous communication (9), a satisfactory and reproducible automated method for the estimation of total hydroxyproline in urine with the Auto Analyzer, we felt it worthwhile to use the strong cation exchange resin tablets of Hypronosticon in our own method and compare the results thus obtained with the original method, as well as with that of Bergman \& Loxley (10). We now report an automated method using strong cation exchange resin tablets of Hyprono- 
sticon for the assay of total urinary hydroxyproline and discuss the relative merits of this and the two methods already referred to.

\section{Materials and Methods}

\section{Chemicals}

Hypronosticon resin tablets (N.V. Organon oss, Holland), hydroxy- $L$-proline (calbiochem, A grade); the other chemicals were from Merck'(p.a grade).

\section{Apparatus}

The Technicon Auto Analyzer components assembly and preparation of reagents for the automated determination of hydroxyproline are described in a previous communication (9).

\section{Method}

The urine samples were hydrolysed and neutralised according to the method of Goverde \& Veenkamp (4).

After neutralisation, distilled water was added up to about the $2.5 \mathrm{ml}$ mark; the suspension was then homogenized in a vibrating mixer and centrifuged for $5 \mathrm{~min}$ at about $1000 \mathrm{rpm}$. The supernatant was carefully collected in a volumetric flask.

About $2.5 \mathrm{ml}$ of distilled water was again added to all the tubes, followed by homogenization and centrifugation as before. The superantant was collected in the same flask containing the first portion and the volume was made up exactly to $5 \mathrm{ml}$ with distilled water and again centrifuged. One drop of $2 \mathrm{~mol} / 1 \mathrm{HCl}$ was added to the supernatant to eliminate the indicator colour.

One $\mathrm{ml}$ aliquots of the samples were then transfered to Auto Analyzer cups and placed on the sampler II, alternating with water cups to give a double wash and run at 30 cups per hour. Hydroxyproline standards preceed each run and the determinations were carried out using the flow diagram in figure 1.

The reliability of the present method was tested by the recovery of hydroxyproline under various conditions as follows:

a) The effect of urine components on the percentage recovery of hydroxyproline was tested by adding internal hydroxyproline standards to the urine samples after (tab. 1) and before (tab. 2) hydrolysis; the results were compared to those of Delfosse et al (9) and Bergman \& Loxley (10) respectively.

b) Three aliquots of different urine samples were analysed according to the proposed method and the methods of Delfosse et al (9) and Goverde \& Veenkamp (4).

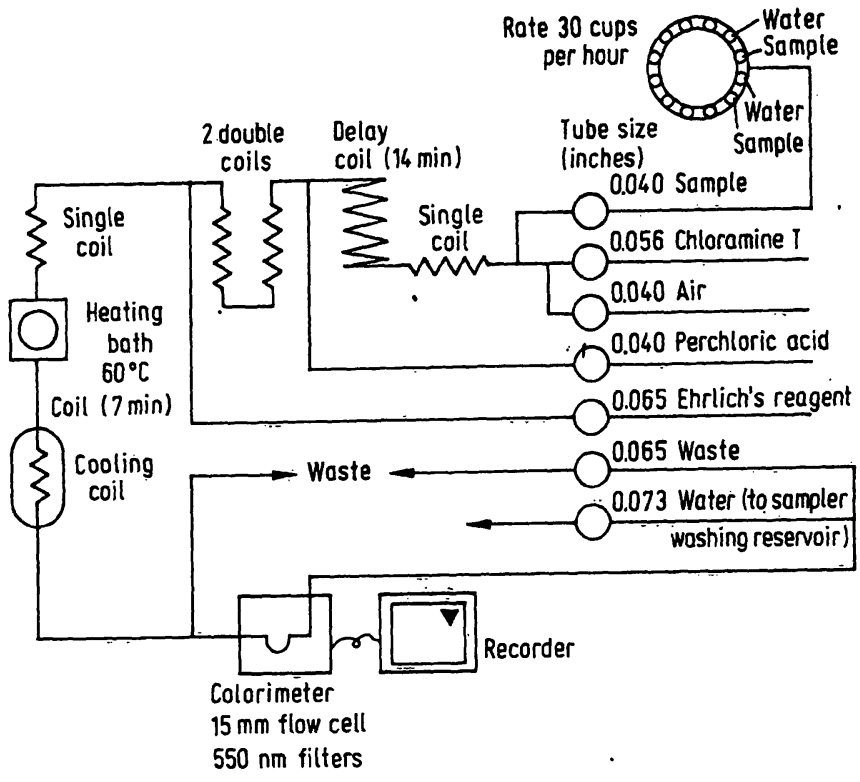

Fig. 1. Flow diagram for hydroxyproline determination.

\section{Results and Discussion}

The results pertaining to the percentage recovery of hydroxyproline, obtained by adding known amounts of standard hydroxyproline to the urine samples after hydrolysis are presented in table 1 . The three methods viz., present method, Delfosse et al (9) and Bergman \& Loxley (10) yielded recoveries of $89.2-93.0 \%$ (mean 91.1), 88.5-97.0 (mean 91.8) and 81.6-96.5\% (mean $88.6)$ respectively.

Table 2 shows the results obtained on the percentage recovery of hydroxyproline by adding internal standards to the urine samples before hydrolysis. In the present method the recoveries ranged between 83.4-90.4\% (mean 87.1) while the methods of Delfosse et al (9) and Bergman \& Loxley (10) resulted in recoveries of 88.9$92.0 \%$ (mean 90.1) and 73.1-84.1\%(mean 76.8) respectively.

Tab. 1. Percentage recovery of standard hydroxyproline added after hydrolysis of urine samples.

$$
\text { Proposed method }
$$

Amount of internal Hydroxyproline Percentage standard added recovered ${ }^{\mathrm{a}} \quad$ recovery ${ }^{\mathrm{c}}$ ( $\mu \mathrm{g})$ ( $\mu \mathrm{g})$

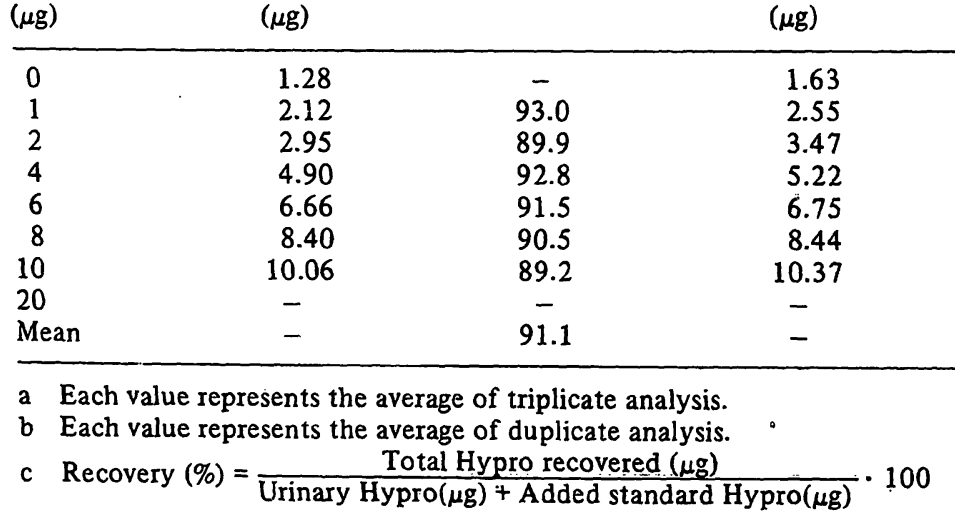

$$
\text { Delfosse et al (9) }
$$

Bergman \& Loxley (10)

\begin{tabular}{llll}
$\begin{array}{l}\text { Hydroxyproline } \\
\text { recovered } \\
(\mu \mathrm{g})\end{array}$ & $\begin{array}{l}\text { Percentage } \\
\text { recovery }^{\mathrm{c}}\end{array}$ & $\begin{array}{l}\text { Hydroxyproline } \\
\text { recovered }^{\mathrm{b}} \\
(\mu \mathrm{g})\end{array}$ & $\begin{array}{l}\text { Percentage } \\
\text { recoveryc }\end{array}$ \\
\hline 1.63 & - & 4.80 & - \\
2.55 & $9 \overline{7.0}$ & 5.60 & 96.5 \\
3.47 & 95.6 & 6.35 & 93.4 \\
5.22 & 92.7 & 7.55 & 85.8 \\
6.75 & 88.5 & 9.80 & 90.7 \\
8.44 & 87.6 & - & - \\
10.37 & 89.2 & 12.40 & 83.8 \\
- & - & 20.25 & 81.6 \\
- & 91.8 & - & 88.6 \\
\hline
\end{tabular}


Tab. 2. Percentage recovery of standard hydroxyproline added before hydrolysis of urine samples.

\begin{tabular}{|c|c|c|c|c|c|c|}
\hline \multirow[b]{2}{*}{$\begin{array}{l}\text { Amount of internal } \\
\text { standard added } \\
(\mu \mathrm{g})\end{array}$} & \multicolumn{2}{|l|}{ Proposed method } & \multicolumn{2}{|l|}{ Delfosse et al (9) } & \multicolumn{2}{|c|}{ Bergman \& Loxley (10) } \\
\hline & $\begin{array}{l}\text { Hydroxyproline } \\
\text { recovered }{ }^{\mathrm{a}} \\
(\mu \mathrm{g})\end{array}$ & $\begin{array}{l}\text { Percentage } \\
\text { recoveryc }\end{array}$ & $\begin{array}{l}\text { Hydroxyproline } \\
\text { recovered }^{\mathrm{a}} \\
(\mu \mathrm{g})\end{array}$ & $\begin{array}{l}\text { Percentage } \\
\text { recoveryc }\end{array}$ & $\begin{array}{l}\text { Hydroxy proline } \\
\text { recovered } \mathrm{b} \\
(\mu \mathrm{g})\end{array}$ & $\begin{array}{l}\text { Percentage } \\
\text { recoveryc }\end{array}$ \\
\hline $\begin{array}{c}0 \\
2 \\
4 \\
6 \\
8 \\
10 \\
\text { Mean }\end{array}$ & $\begin{array}{c}1.23 \\
2.92 \\
4.48 \\
6.34 \\
7.70 \\
9.93 \\
-\end{array}$ & $\begin{array}{c}- \\
90.4 \\
85.7 \\
87.7 \\
83.4 \\
88.4 \\
87.1\end{array}$ & $\begin{array}{r}1.65 \\
3.36 \\
5.08 \\
6.87 \\
8.68 \\
10.36 \\
-\end{array}$ & $\begin{array}{l}-\overline{2} .0 \\
89.9 \\
89.8 \\
89.9 \\
88.9 \\
90.1\end{array}$ & $\begin{array}{c}2.46 \\
3.75 \\
4.72 \\
6.40 \\
8.02 \\
9.29 \\
-\end{array}$ & $\begin{array}{c}- \\
84.1 \\
73.1 \\
75.6 \\
76.7 \\
74.6 \\
76.8\end{array}$ \\
\hline
\end{tabular}

a Each value represents the average of triplicate analysis.

b Each value represents the average of duplicate analysis.

c Percentage recovery of internal standard was calculated as before.

Thus it can be seen that the best recoveries are obtained using the technique described in the present work by adding internal standards after hydrolysing the urine (tab. 1) and the results are comparable with those of the automated method reported previously (9). When the internal standards were added before hydrolysis of urine, the average percentage recovery appeared to be lower (87.1\%) in the present method than in our automated method $(90.1 \%)$.

However, the differences are small and may be not significant. These results therefore suggest that the proposed method is satisfactory.

The reliability of the proposed method was also assessed by analysing the same urine samples using different methods and the results are presented in table 3 . It can be seen that the urinary hydroxyproline values agree between the methods of Delfosse et al (9) and Goverde \& Veenkamp (4).

These results are also in agreement with those of Burkhardt et al (6). However, the present method gave values that were consistently about ten percent lower than those obtained by the method of Delfosse et al (9).

While good recoveries are obtained using the technique described in the present work by adding the internal standards either before or after hydrolysis of the urine, it is noteworthy that the difference introduced by hydrolysis in the presence of resin in the present method, suggests that the latter is responsible for the lower urinary hydroxyproline values compared with the previous technique (9) (tab. 3). Results from the determinations of standard hydroxyproline suggest (unpublished results) a loss of the amino acid after hydrolysis in the presence of the resin (3.2\%). When compared with the method of Delfosse et al (9), the loss amounts to $11.6 \%$ (tab. 3), providing the hydrolysis in presence of resin is performed on urine and not merely on hydroxyproline solutions.
Tab. 3. Hydroxyproline in urine samples using three different methods of assay.

\begin{tabular}{|c|c|c|c|}
\hline \multirow[b]{2}{*}{$\begin{array}{l}\text { No. } \\
\text { of sample }\end{array}$} & \multicolumn{3}{|c|}{ Amount of hydroxyproline (mg/l urine) } \\
\hline & $\begin{array}{l}\text { Proposed } \\
\text { method }^{\mathrm{a}}\end{array}$ & $\begin{array}{l}\text { Delfosse } \\
\text { et } a^{\mathrm{a}}\end{array}$ & $\begin{array}{l}\text { Goverde } \\
\text { \& Veenkamp }\end{array}$ \\
\hline 1 & 12.6 & 13.0 & 13.2 \\
\hline 2 & 28.0 & 31.6 & 32.9 \\
\hline 3 & 46.5 & 54.6 & 56.9 \\
\hline 4 & 31.3 & 33.5 & 32.6 \\
\hline 5 & 49.5 & 57.3 & 54.2 \\
\hline
\end{tabular}

a Each value represents the average of triplicate analysis. b Each value represents the average of duplicate analysis.

Although the difference might be due to the effect of interfering substances in urine it is nevertheless difficult to understand why the same difference is not found between the methods of Delfosse et al (9) and Goverde \& Veenkamp (4) respectively (tab. 3).

However, one of the two time consuming steps (namely drying) does not involve any manipulation and the comparison between the automated technique using $\mathrm{HCl}$ hydrolysis and the present method using resin hydrolysis rests upon the amount of samples to be treated; considered on a time basis it would appear to favour the latter.

This advantage must be weighed against the lower urinary hydroxyproline values. Nonetheless, the results obtained by the present method are consistent. They are meaningful provided the same procedure is followed throughout the course of an experimental study.

\section{Acknowledgements}

This work was supported by a grant of the National Bank of Belgium to the Rheumatology Laboratory (V.U.B. -U.L.B.).

The authors also thank Miss $L$. Hennes for her valuable technical assistance during the course of this work. 


\section{References}

1. Prockop, D. J. \& Kivirikko, K. I., (1967). Ann. Intern. Med. 66, 1243-1266.

2. Birkenhager, J. C., (1970), Folia Med. Neerl. 13, 79-87.

3. Ziff, M., Kibrick, A., Dresner, E. \& Griebetz, H. J., (1956), J. Clin. Invest. 35, 579-587.

4. Goverde, B. C. \& Veenkamp, F. J. N., (1972), Clin. Chim. Acta. 41, 29-40.

5. Grant, R. A., (1964). J. Clin. Pathol. 17, 685-686.

6. Burkhardt, H., Burkhardt, F. \& Rommel, K., (1973). Deut. Med. Wochenschr. 98, 1847-1852.

7. Burkhardt, H., Burkhardt, F., Wepler, R. \& Rommel, K., (1974). this j. 12, 108-115.

8. Kivirikko, K. I., Laitinen, O. \& Prockop, D. J., (1967). Anal. Biochem. 19, 249-255.

9. Delfosse, L., Orloff, S., Rao, V. H., Strosberg, E. \& Verbruggen, L. Indian J. Biochem. Biophys. In Press

10. Bergman, I. \& Loxley, R., (1963). Analyt. Chem. 35, 19611965.

Prof. Dr. S. Orloff Lab. of Rheumatology Brugmann Univ. Hosp: Van Gehuch tenplein 4 B-1020 Brussels/Belgium 